\title{
Exposure to indoor allergens in early infancy and sensitization
}

\author{
Abul Kashem M. Munir, MD, MPH, PhD, N-I. Max Kjellman, MD, PhD, and \\ Bengt Björkstén, MD, PhD Linköping, Sweden
}

\begin{abstract}
Background: Indoor allergens play a major role both in sensitization and as triggers of asthma in children. The relationship between allergen exposure and sensitization to cats, dogs, and mites was studied prospectively in 100 newborn babies with a history of allergy in both parents. Methods: Skin prick tests were done with Dermatophagoides pteronyssinus, $D$. farinae, and cat and $\operatorname{dog}$ allergens in all the children at 6 and 18 months of age and in 86 children at 5 years of age. Dust samples were collected from the homes during infancy and at 5 years. The parents of the children responded to a questionnaire focused on environmental factors that could influence indoor allergen levels. In addition, dust samples were collected from the day-care centers of the sensitized children. The allergen levels were determined by ELISA. Results: The levels of the major cat allergen, Fel d 1, varied from $0.02 \mu \mathrm{g}$ to $6.8 \mu \mathrm{g} / \mathrm{gm}$ (geometric mean [GM], $0.4 \mu \mathrm{g} / \mathrm{gm}$ ) during infancy and less than $0.02 \mu \mathrm{g}$ to $13 \mu \mathrm{g} / \mathrm{gm}$ dust (GM, $0.12 \mu \mathrm{g} / \mathrm{gm}$ ) at age 5 years. Dog allergen, Can $\mathrm{f} 1$, levels ranged from $0.18 \mu \mathrm{g}$ to $590 \mu \mathrm{g} / \mathrm{gm}$ (GM, $3.1 \mu \mathrm{g} / \mathrm{gm}$ ) in infancy and $0.09 \mu \mathrm{g}$ to $13 \mu \mathrm{g} / \mathrm{gm}$ at age 5 years $(\mathrm{GM}, 0.6 \mu \mathrm{g} / \mathrm{gm})$. Eleven children $(13 \%)$ were sensitive to cats, and three were sensitive to dogs at 5 years of age. They had been exposed to similar levels of allergen as the nonsensitized children. The levels of mite allergen (Der $p 1+$ Der $\mathbf{f} 1$ ) at age 1 year varied from less than $0.02 \mu \mathrm{g}$ to $1 \mu \mathrm{g} / \mathrm{gm}$ dust (GM, $0.12 \mu \mathrm{g} / \mathrm{gm})$ and at age 5 years from less than $0.02 \mu \mathrm{g}$ to $3.5 \mu \mathrm{g} / \mathrm{gm}(\mathrm{GM}, 0.05 \mu \mathrm{g} / \mathrm{gm}$ ) dust. Only two homes contained mite allergen levels greater than 2 $\mu \mathrm{g} / \mathrm{gm}$ dust. The levels were less than $0.3 \mu \mathrm{g} / \mathrm{gm}$ dust in all but one sample from the day-care centers. Only one child was sensitized to mites at age 5 years. The mite allergen level was less than $0.1 \mu \mathrm{g} / \mathrm{gm}$ at home, and he did not attend a day-care center.
\end{abstract}

Conclusions: The findings indicate that exposure to low levels of indoor allergens in early childhood is associated with a low incidence of sensitization. However, levels well below currently suggested threshold levels may cause sensitization in children with a family history of allergy. We suggest that a fixed threshold risk level for allergic sensitization may not be appropriate in all climates. (J Allergy Clin Immunol 1997; 100:177-81.)

Key words: High-risk children, indoor allergens, ELISA, sensitization

From the Department of Health and Environment, Division of Pediatrics, University Hospital, Linköping, Sweden.

Supported by grants from The Swedish Asthma and Allergy Association, The Swedish Society of Medicine, The National Board of Health and Welfare, and the Swedish Medical Research Council (grant no. 7510).

Received for publication Oct. 8, 1996; revised Mar. 5, 1997; accepted for publication Mar. 13, 1997.

Reprint requests: Abul Kashem M. Munir, MD, MPH, PhD, Department of Pediatrics, University Hospital, 14th Floor, 58185 Linköping, Sweden.

Copyright $(1997$ by Mosby-Year Book, Inc.

$0091-6749 / 97 \$ 5.00+0 \quad \mathbf{1} / \mathbf{1 / 8 2 1 5 4}$

\author{
Abbreviations used \\ CI: Confidence interval \\ GM: Geometric mean \\ HDMs: House dust mites
}

Mites, cats, and dogs are common sources of indoor allergens, and they play a major role both in sensitization and as triggers of asthma in children in various parts of the world. ${ }^{1-7}$ A relationship between exposure to mite allergens and sensitivity, as judged by positive skin test results and/or the presence of circulating $\operatorname{IgE}$ antibodies, ${ }^{1-4}$ has been suggested in several studies, although there are other studies in which such relationships were not identified. 8,9

Similar studies of the relationship between exposure to and sensitivity for pet allergens have not been conducted. Despite this, risk levels for sensitization have been suggested (i.e., between 1 and $8 \mu \mathrm{g} / \mathrm{gm}$ dust for Fel d $1,{ }^{10} 10 \mu \mathrm{g} / \mathrm{gm}$ dust for Can $\mathrm{f} 1,{ }^{11}$ and $2 \mu \mathrm{g} / \mathrm{gm}$ for Der $\mathrm{p} 1 / \mathrm{Der} \mathrm{f} 1 .^{5}$ )

Exposure to indoor allergens may occur at any time, but the conditions under which exposure takes place early in life seem to be particularly important for sensitization. ${ }^{12-15}$ The process of sensitization is infuenced by environmental factors (e.g., infections and air pollution). ${ }^{14,15}$ Recent studies show that even very low doses of allergen may induce a $\mathrm{T}-$-cell response to the allergen. ${ }^{16}$

The aim of the study was to investigate prospectively the relationship between exposure to major cat (Fel d 1), $\operatorname{dog}(\operatorname{Can} \mathrm{f} 1$ ), and mite (Der p 1/Der $\mathrm{f} 1$ ) allergens in house dust and sensitivity at 5 years of age in a group of children with a family history of allergy. We have previously published a study on the influence of environmental factors on the levels of indoor allergens in the homes of these children. ${ }^{17}$

\section{METHODS}

The study group comprised 100 children born in Linköping, Sweden, between 1987 and 1990 who had two allergic parents. The cohort was followed up on a yearly basis for the first 5 years of life. At 1 and 5 years, the parents responded to a questionnaire regarding the conditions of the house, the presence of furred pets (cats or dogs), smoking habits, and any visits with the child to other regions of Sweden or to other countries.

Skin prick tests were performed at 6 and 18 months of age and at 5 years according to the recommendations of the European Academy of Allergy and Clinical Immunology ${ }^{18}$ by 
TABLE I. Peak cat, dog, and mite allergen levels in dust from homes and day-care centers of children who were sensitized to the respective allergens

\begin{tabular}{|c|c|c|c|c|c|c|}
\hline \multirow[b]{2}{*}{ Children } & \multicolumn{2}{|r|}{$\begin{array}{c}\text { Cat } \\
\text { (Fel d 1) }\end{array}$} & \multicolumn{2}{|r|}{$\begin{array}{c}\text { Dog } \\
\{\text { Can } f 1\}\end{array}$} & \multicolumn{2}{|c|}{$\begin{array}{c}\text { Mite } \\
(\operatorname{Der} p 1+\operatorname{Der} \mathrm{f})\end{array}$} \\
\hline & $n$ & $\mu \mathrm{g} / \mathrm{gm}$ & $n$ & $\mu \mathrm{g} / \mathrm{gm}$ & $n$ & $\mu g / g m$ \\
\hline Sensitized & 11 & $\begin{array}{c}0.35 \\
(0.15-0.90)\end{array}$ & 3 & $\begin{array}{c}8.1 \\
(0.20-337)\end{array}$ & 1 & $0.08 \dagger$ \\
\hline Nonsensitized & 75 & $\begin{array}{c}0.40 \\
(0.10-1.5)\end{array}$ & 83 & $\begin{array}{c}2.5 \\
(0.50-13)\end{array}$ & 85 & $\begin{array}{c}0.13 \\
(0.03-0.50)\end{array}$ \\
\hline
\end{tabular}

Geometric mean values \pm 2 SD are given. Sensitivity was determined by skin prick tests. None of the differences between sensitized and nonsensitized children were statistically significant

$\doteqdot$ Only one child was sensitive to mites.

the same nurse. The tests were done with a panel of six allergens (Dermatophagoides pteronyssinus, D. farinae, cat, dog, birch, and timothy grass pollen extracts), histamine $(10 \mathrm{mg} / \mathrm{ml})$, and a negative control by using Solu Prick extracts and lancets (ALK, Hørsholm, Denmark). A mean skin wheal diameter 3 $\mathrm{mm}$ or greater than that of the negative control was regarded as a positive reaction and indicative of atopy. In all, 86 of the 100 children were available for skin prick tests at 5 years of age.

Dust samples were collected during infancy and again at the age of 5 years. During the first year, dust sampling was done four times (i.e., during the four seasons). Because the highest allergen levels were found in October and December, ${ }^{17}$ the samples at age 5 were only collected during that period. In addition, dust samples were collected from day-care centers of the children who were sensitized to either pets or mites at 5 years of age. The collection procedure has been described previously. ${ }^{19}$ Briefly, the child's mattress and a carpet in the living room were vacuum-cleaned for 2 minutes per square meter and the floor area for 1 minute per square meter. The samples obtained during the first year of life were collected in paper bags, and the dust samples at 5 years were collected with cellulose paper filters (ALK). At least two dust samples were available from 86 homes. In all, 542 dust samples were available for analysis ( 351 samples from the first year, 180 samples at 5 years, and 11 samples from day-care centers).

The dust samples were sieved through a $300 \mu \mathrm{m}$ mesh and weighed. After aqueous extraction, the contents of major allergens from cats (Fel d 1), dogs (Can f 1), and mites (Der p 1, Der $f$ 1) were determined by using a sandwich ELISA with monoclonal antibodies? The cutoff limit for cat and mite ELISA was $0.02 \mu \mathrm{g} / \mathrm{gm}$ dust, and for dog ELISA it was 0.06 $\mu \mathrm{g} / \mathrm{gm}$ dust. The levels of Der $\mathrm{p} 1$ and Der $\mathrm{f} 1$ were combined in the processing of data. The analysis of a possible relationship between sensitivity and allergen exposure was based on the highest allergen level in the samples from each home.

The ELISA results were transformed into decimal logarithms. However, even after log-transformation, the distribution was skewed, Therefore nonparametric statistical methods were chosen for analysis of data. The Mann-Whitney U test was used to determine the levels of significance between groups. The Wilcoxon signed-rank test was used to examine any variation between sampling sites.

The study was approved by the Ethics Committee for Human Research at the University Hospital of Linköping. Oral or written consent was obtained from all the parents.

\section{RESULTS \\ Sensitivity to indoor allergens}

In all, 11 of 86 children (13\%) were sensitized to at least one inhalant allergen at 5 years of age: all of them were sensitized to cats, three to dogs, and only one to mites. The geometric mean (GM) exposure levels to all three allergens were similar in sensitized and nonsensitized children (Table I).

All but one of the 11 children with cat sensitivity were exposed to less than $1 \mu \mathrm{g}$ of Fel $\mathrm{d} 1$ per gram of dust, and six children were exposed to less than $0.5 \mu \mathrm{g}$ of Fel d 1 per gram of dust (Fig. 1 and Table II). Seventeen of 19 children $(89 \%)$ who were exposed to cat or dog allergen levels of $8 \mu \mathrm{g} / \mathrm{gm}$ of dust or greater were not sensitized to these allergens. Seven children had a cat and eight children had a dog at home at 5 years of age or earlier. One of them was sensitized to cats and one to dogs.

The mite allergen level in the home of the only child with mite sensitivity was less than $0.1 \mu \mathrm{g} / \mathrm{gm}$. The child did not attend a day-care center and had not visited areas where mite infestation is common. Three children were exposed to mite allergen levels of more than $2 \mu \mathrm{g} / \mathrm{gm}$ dust at home or in a day-care center, and none of them were sensitized to mites. Most of the families (51 of 86) visited regions where mite infestation is common (e.g., the coastal region of Southern and Western Sweden, the British Isles or other parts of Europe, and the United States) at least once for periods of 2 to 4 weeks.

\section{Exposure to indoor allergens}

During the first year of life, the cat allergen levels at home varied from $0.02 \mu \mathrm{g} / \mathrm{gm}$ to $6.8 \mu \mathrm{g} / \mathrm{gm}$ dust (GM 0.4 $\mu \mathrm{g} ; 95 \%$ confidence interval [CI] $0.26-0.50 \mu \mathrm{g} / \mathrm{gm}$ dust) (Fig. 1). Cat allergens were detected in all homes, and the levels were above $1 \mu \mathrm{g} / \mathrm{gm}$ dust in $27(38 \%)$ of them.

At 5 years, cat allergen was detected in all but one home, but the levels were lower than those detected during infancy $(p<0.01)$. The allergen levels varied from less than $0.02 \mu \mathrm{g}$ to $13 \mu \mathrm{g} / \mathrm{gm}$ dust (GM, $0.12 \mu \mathrm{g}$; $95 \%$ CI, $0.09-0.20 \mu \mathrm{g} / \mathrm{gm}$ dust). Three $(5 \%)$ homes contained Fel d 1 levels greater than $1 \mu \mathrm{g} / \mathrm{gm}$, and one home had levels of more than $8 \mu \mathrm{g} / \mathrm{gm}$ dust. Dog allergen was detected in all the homes during infancy, and the levels varied from $0.18 \mu \mathrm{g} / \mathrm{gm}$ to $590 \mu \mathrm{g} / \mathrm{gm}$ dust (GM $3.1 \mu \mathrm{g} ; 95 \% \mathrm{CI}, 1.9-4.8 \mu \mathrm{g} / \mathrm{gm}$ dust). In 15 homes $(21 \%)$ the Can $\mathrm{f} 1$ levels were greater than $8 \mu \mathrm{g} / \mathrm{gm}$ dust. The majority of these households ( 10 of 15 ) had no dog.

The dog allergen levels at 5 years varied between 0.09 $\mu \mathrm{g}$ and $13 \mu \mathrm{g} / \mathrm{gm}$ dust (GM, $0.6 \mu \mathrm{g} ; 95 \% \mathrm{CI}, 0.45-0.77$ $\mu \mathrm{g} / \mathrm{gm}$ dust). Two homes ( $3 \%$ ) had Can $\mathrm{f} 1$ levels of more than $8 \mu \mathrm{g} / \mathrm{gm}$ dust. The levels were lower than during the first year of life $(p<0.01)$.

The mite allergen levels at home varied from less than $0.02 \mu \mathrm{g}$ to $1 \mu \mathrm{g} / \mathrm{gm}$ dust (GM, $0.12 \mu \mathrm{g}$; $95 \%$ CI, 0.08-0.16 $\mu \mathrm{g} / \mathrm{gm}$ dust) during the first year of life. Mite allergens were not detected in 10 homes (14\%). At year 5, mite 


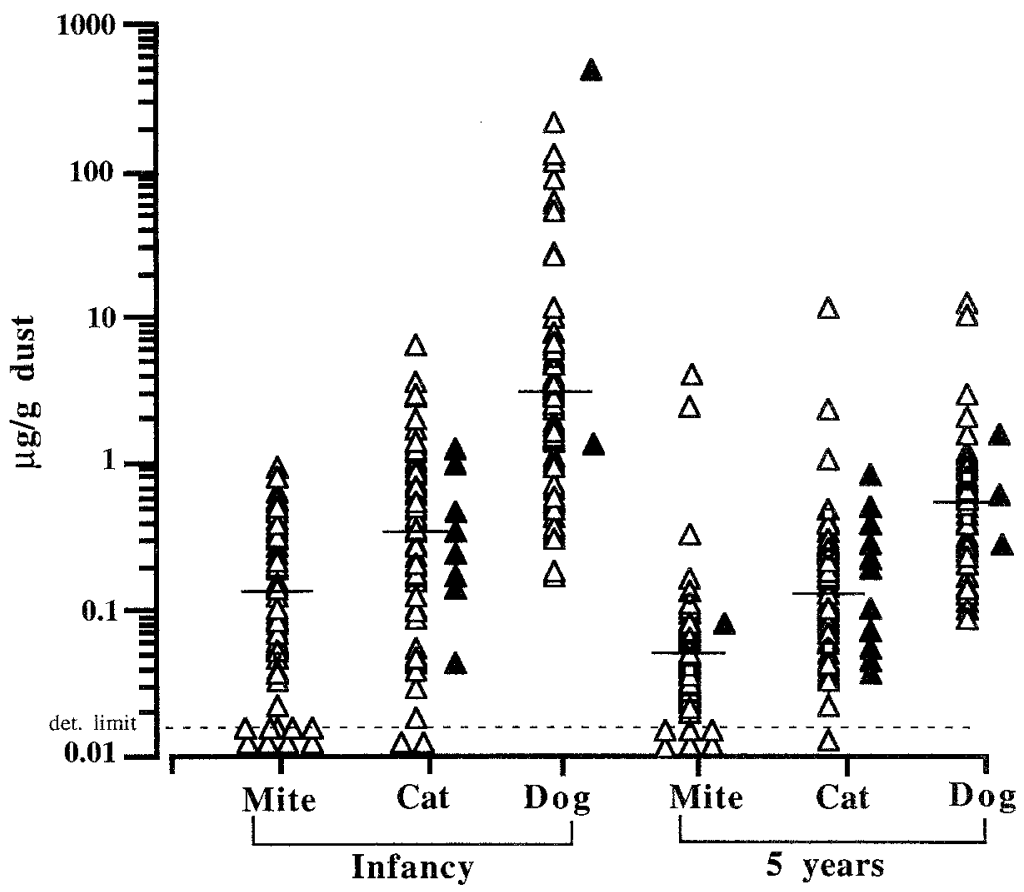

FIG. 1. Highest levels of mite (Der p $1+\operatorname{Der} f 1$ ), cat (Fel d 1), and dog (Can $f$ 1) allergens in dust samples collected from 86 homes of children with a history of allergy in both parents during infancy and at 5 years of age. Bars indicate GM values for the respective allergens. Filled symbols indicate levels in homes of children who were sensitized to the allergen.

allergen was detected in four of these homes. The levels were low, ranging from 0.025 to $0.085 \mu \mathrm{g} / \mathrm{gm}$ dust.

The mite allergen levels were lower at 5 years than during infancy ( $p<0.01$ ), that is, between less than 0.02 $\mu \mathrm{g}$ and $3.5 \mu \mathrm{g} / \mathrm{gm}$ dust (GM, $0.05 \mu \mathrm{g} ; 95 \% \mathrm{CI}, 0.04-0.07$ $\mu \mathrm{g} / \mathrm{gm}$ dust). In $12 \%$ of the homes no mite allergens were found, and three homes had mite allergen levels greater than $2 \mu \mathrm{g} / \mathrm{gm}$ dust.

The levels of mite, cat, and dog allergens in dust from the day-care centers of the sensitized children were similar to those recorded in the homes (Table I).

\section{DISCUSSION}

Sensitization to indoor allergens during the first 5 years of life may occur at lower home dust allergen levels than generally suggested. All but one of the children sensitized to cat in our study were exposed to less than 1 $\mu \mathrm{g}$ of cat allergen per gram of dust, and six of them were exposed to less than $0.5 \mu \mathrm{g} / \mathrm{gm}$ dust. Similarly, two of the three children sensitized to dog were exposed to less than $1.5 \mu \mathrm{g}$ of dog allergen per gram of dust, and the only child with mite sensitivity was exposed to less than $0.1 \mu \mathrm{g} / \mathrm{gm}$ dust at home during the first 5 years of life.

Pet allergens are ubiquitous in various public places. Thus children may be exposed to high levels of pet allergens in day-care centers and in schools. ${ }^{20,21}$ The levels of cat and dog allergen were similar to those reported previously from the same area. ${ }^{20-24}$ In this study we also investigated exposure in day-care centers of the sensitized children and found that none of the children
TABLE II. Peak exposure levels of indoor allergens at home and in day-care centers in 11 children who were sensitive to cat, dog, and/or mite during their first 5 years of life

\begin{tabular}{|c|c|c|c|}
\hline \multirow[b]{2}{*}{$\begin{array}{l}\text { Child's } \\
\text { code no. }\end{array}$} & \multicolumn{3}{|c|}{$\begin{array}{l}\text { Highest allergen level at home or in day-care center } \\
\qquad(\mu \mathrm{g} / \mathrm{gm} \text { dust) }\end{array}$} \\
\hline & $\begin{array}{c}\text { Cat } \\
\text { (Fel d 1) }\end{array}$ & $\begin{array}{c}\text { Dog } \\
(\operatorname{Can} f 1)\end{array}$ & $\begin{array}{c}\text { Mite } \\
(\operatorname{Der} p 1+\operatorname{Der} f 1)\end{array}$ \\
\hline D4 & $\underline{0.06}$ & 0.21 & 0.04 \\
\hline D14 & 0.44 & 1.4 & 24 \\
\hline $\mathrm{D} 22$ & $\overline{0.51}$ & $\overline{1.2}$ & 0.3 \\
\hline D47 & 1.3 & $\underline{586 \dagger}$ & 0.4 \\
\hline D51 & 1.0 & 2.0 & 5.4 \\
\hline D53 & $\underline{0.4}$ & 1.3 & 0.09 \\
\hline D61 & $\overline{0.56}$ & 1.7 & 0.08 \\
\hline D88 & $\overline{0.36}$ & $122 \div$ & 0.3 \\
\hline D90 & 0.34 & $\underline{0.64}$ & $\underline{0.08}$ \\
\hline D98 & $\overline{0.56}$ & $\overline{1.0}$ & $\overline{0.2}$ \\
\hline D124 & 0.26 & 2.2 & 0.12 \\
\hline
\end{tabular}

Skin prick tests were performed at 6 and 18 months and 5 years of age. Sensitivity to an allergen is indicated by underlining of the allergen concentration.

$\uparrow$ Had a dog at home previously.

$\leftarrow$ Had a cat at home previously.

was exposed to more than $1.3 \mu \mathrm{g}$ of cat allergen in a day-care center.

It has been suggested that Fel $d 1$ levels greater than $8 \mu \mathrm{g} / \mathrm{gm}$ dust should be regarded as a risk for sensitiza- 
tion to cats. ${ }^{10}$ Recently, this level was re-evaluated, and it was suggested that levels as low as $1 \mu \mathrm{g} / \mathrm{gm}$ can cause sensitization (Third International Workshop on Indoor Allergens and Asthma, Cuenca, Spain, 1995). We could not confirm the presence of a certain threshold level, because exposure to less than $0.5 \mu \mathrm{g}$ of Fel d 1 per gram of dust at home was associated with sensitivity in children with a family history of atopy.

Our study supports a recent German report that about $50 \%$ of children with at least one atopic parent had serum $\operatorname{IgE}$ antibodies against cat dander already at 1 year of age. ${ }^{25}$ None of the sensitized children were exposed to more than $0.3 \mu \mathrm{g} / \mathrm{gm}$ of Fel $\mathrm{d} 1$ per gram of dust in their homes.

No risk level for dog allergen has been identified, although $10 \mu \mathrm{g} / \mathrm{gm}$ Can $\mathrm{f} 1$ has been suggested. ${ }^{11} \mathrm{In}$ our study, dog allergen levels as low as $1.5 \mu \mathrm{g} / \mathrm{gm}$ dust were associated with sensitivity.

The allergen levels were lower in year 5 than in year 1 . Because the children were from families in which both parents were allergic, awareness about the risk of the children and improved cleaning are the most likely explanations.

Our study also confirms that the levels of mite allergen are low in Sweden ${ }^{20-23,26}$ and that sensitization seems to occur at lower levels than those generally suggested by studies in countries with a warmer and more humid climate. ${ }^{5}$ The only child who had sensitivity to mites during the first 5 years of age was exposed to less than $0.1 \mu \mathrm{g}$ of mite allergens at home. In a British prospective study of children with one atopic parent, $40 \%$ of the children were sensitized to house dust mites (HDMs) at 5 years of age. ${ }^{1}$ In that study, however, the mite allergen levels were high (GM of Der p 1, $16.8 \mu \mathrm{g} / \mathrm{gm}$ ). The big difference in mite allergen concentrations in our study in comparison with the British study is probably due to the different climate. The winters in most parts of Sweden are too cold and dry for mites to survive. Higher levels of mite allergens are therefore only found in homes with increased humidity, possibly as a result of poor ventilation. ${ }^{21,26}$

In a German study the cumulative incidence of sensitization to HDMs up to the age 3 years was similar in children who were exposed to mite allergen levels below and above $1.2 \mu \mathrm{g} / \mathrm{gm} .{ }^{27}$ Recently, in another German prospective population-based study of school children, Kuehr et al. ${ }^{28}$ reported that many of the HDM-sensitized children were exposed to mite allergen levels less than $0.3 \mu \mathrm{g} / \mathrm{gm}$ dust. The German studies suggest that exposure to even low levels of mite allergens may cause sensitivity and that there is no particular threshold.

In contrast to the findings in Germany, ${ }^{27,28}$ only one of the 86 children in our study was sensitized to HDMs during the first 5 years of life, despite a strong family history of allergic disease. This would indicate that other environmental factors operating in early life may modify the incidence of sensitization. The conclusions from all of these studies would be that exposure to high levels of mite allergens increases the risk for sensitization and that sensitization may occur at levels well below the suggested threshold levels. Although exposure to low levels of allergen does not commonly induce clinically apparent sensitivity, exposure to low levels of HDMs is sufficient for initial T-cell priming in infants. ${ }^{16}$

Because sensitivity to HDMs was apparent in only one of the children, despite the fact that most of them had visited areas with high mite infestation, it seems reasonable to also conclude that temporary visits to miteinfested areas are not a likely cause of sensitization in children who are normally exposed to only low levels of mite allergens. This notion is supported by our recent finding that the levels of mite allergens were less than 0.1 $\mu \mathrm{g}$ in $76 \%$ of the homes of HDM-sensitive children with perennial symptoms of asthma. ${ }^{29}$

Repeated inhalation of low doses of allergen can induce bronchial hyperreactivity in sensitive subjects. ${ }^{30}$ Possibly, in areas of low mite infestation, repeated inhalation of low doses of allergen for long periods could also induce sensitization, which would be apparent in children older than those in areas with high mite allergen exposure.

There is no direct relationship between exposure and sensitization. Seventeen children were exposed to dog allergen levels greater than $8 \mu \mathrm{g} / \mathrm{gm}$, and three children were exposed to more than $2 \mu \mathrm{g}$ of mite allergen per gram of dust, but none of them experienced sensitivity, whereas all children who were sensitized were exposed to lower levels. Furthermore, only two of the 14 children who had a cat or dog at home at any time during the observation period were sensitive to the pets. These observations complicate the analysis of a possible doseresponse relationship between allergen exposure and sensitization, as reported by other investigators. ${ }^{1-3}$ It is known that the dose of allergen triggering symptoms is influenced by variations in individual susceptibility over time. ${ }^{31,32}$ There is at least a 10,000-fold difference in sensitivity (i.e., in the dose inducing symptoms) among sensitized patients. ${ }^{31}$ Similarly, there may be a difference in the dose of allergen inducing sensitization under the influence of various environmental adjuvant factors.

In conclusion, exposure to low or moderate levels of indoor allergen during the first 5 years of life may sensitize children with a family history of allergy. It seems that a single worldwide allergen level cannot be applied as a threshold for allergic sensitization.

We thank Christina Lillman Ringborg for collecting dust samples and Lena Lindell for performing skin prick tests.

\section{REFERENCES}

1. Sporik R, Holgate ST, Platts-Mills TAE, Cogswell JJ. Exposure to house dust mite allergen (Der p 1) and the development of asthma in childhood. N Engl J Med 1990;323:502-7.

2. Arshad SH, Hide DW. Effect of environmental factors on the development of allergic disorders in infancy. $J$ Allergy Clin Immunol 1992;90:235-41.

3. Lau-Schadendorf S, Falkenhorst G, Weber A, Werthmann I, Lind P, Buettner-Goetz $P$, et al. High mite-allergen exposure increases the 
risk of sensitization in atopic children and young adults. $J$ Allerory Clin Immunol 1989;84:718-25.

4. Warner JA, Little SA, Pollock I, Longbottom IL, Warner JO. The influence of exposure to house dust mite, cat, pollen and fungal allergens in the home on primary sensitization in asthma. Pediatr Allergy Immunol 1990;1:79-86.

5. Platts-Mills TAE. Thomas WR, Aalberse RC, Vervloet D, Chapman MD. Dust mite allergens and asthma: Report of a Second International Workshop. J AJlergy Clin Immunol 1992;89:1046-60.

6. Arruda LK, Rizzo MC, Chapman MD, Fernandez-Caldas E, Baggio D, Platts-Mills TAE, et al. Exposure and sensitization to dust mite allergens among asthmatic children in Sao Paulo, Brazil. Clin Exp Allergy 1991;21:433-9.

7. Munir AKM. Exposure to indoor allergens and relation to sensitization and asthma in children [dissertation]. Linköping, Sweden University of Linköping; 1994.

8. Call RS, Smith TF, Moore E, Chapman MD, Platts-Mills TAE Indoor allergen levels in urban and suburban homes of asthmatics in Atlanta, Georgia [abstract]. J Allergy Chin Immunol 1993;91:172

9. Pauli G, Quoix E, Hedelin G, Bessot JC, Ott M, Dietemann A. Mite allergen content in mattress dust of Dematophagoides-allergic asthmatics/rhinitics and matched controls. Clin Exp Allergy 1993;23:60611.

10. Woodfolk JA, Luczynska CM, de Blay F, Chapman MD, Platts-Mills TAE. Cat allergy [editorial]. Ann Allergy 1992;69:273-5.

11. Platts-Mills TAE, Woodfolk JA, Sporik RB, Chapman MD, Heymann PW. Relevance of indoor allergen measurement and the use of avoidance measures in the treatment of allergic disease. Postgraduate course, 51st AAAI Annual Meeting. New York: AAAI; 1995. p. 111-25.

12. Suoniemi I, Björkstén F, Haahtela $T$. Dependence of immediate hypersensitivity in the adolescent period on factors encountered in infancy. Allergy 1981;36:263-8.

13. Aalberse RC, Nieuwenhuys EJ, Hey M, Stapel SO. 'Horoscope effect' not only for seasonal but also for non-seasonal allergens. Clin Exp Allergy 1992;22:1003-6.

14. Holt $P G$. Environmental factors and primary $T$-cell sensitisation to inhalant allergens: reappraisal of the role of infections and air pollution. Pediatr Allergy Immunol 1995;6:1-10.

15. Björkstén B. Risk factors in early childhood for the development of atopic disease. Allergy 1994:49:400-7.

16. Björkstén B, Holt BJ, Baron-Hay MJ, Munir AKM, Holt PG. Low-level exposure to house dust mites stimulates $T$-cell responses during early childhood independent of atopy. Clin Exp Allergy 1996:26:775-9

17. Munir AKM, Einarsson R, Kjellman N-I M, Björkstén B. Mite (Der $p$ 1, Der $f 1$ ) and cat (Fel $d$ ) allergens in homes of babies with a family history of allergy. Allergy 1993;48:158-63.

18. Dreborg S. Skin prick test. In: Björkstén B, Weeke B, editors. Annual meeting of the European Academy of Allergology and Clinical Immunology (EAACI), Postgraduate Course. Allergy 1985; 40(suppl 4):55-6.
19. Dreborg SKG, Einarsson R, Lau S, Munir AKM, Wahn U. Dust sampling for determination of allergen content. Allergy 1995;50 $188-9$

20. Munir AKM, Einarsson R, Schou C, Dreborg SKG. Allergens in school dust. I. The amount of the major cat (Fel $d \mathrm{I}$ ) and $\operatorname{dog}$ ( Can $f$ I) allergens in dust from Swedish schools is high enough to probably cause perennial symptoms in most asthmatic children sensitized to cat and dog. J Allergy Clin Immunol 1993;5:1067-74.

21. Munir AKM, Einarsson, Dreborg S. Mite (Der p I, Der $f$ I), cat (Fel d I) and dog (Can $f$ l) allergens in dust from Swedish day-care centers. Clin Exp Allergy 1995;25:119-26.

22. Munir AKM, Björkstén B, Einarsson R, Schou C, Ekstrand-Tobin A, Warner A, et al. Cat (Fel $d \mathrm{I})$, dog ( Can $f \mathrm{I})$ and cockroach allergens in homes of asthmatic children from three climatic zones in Sweden. Allergy 1994;49:508-16.

23. Munir AKM. Björkstén B, Einarsson R, Ekstrand-Tobin A, Warner $A$, Kjellman N-IM. Mite allergens in relation to home conditions and sensitization of asthmatic children from three climatic regions. Allergy 1995;50:55-64.

24. Munir AKM, Einarsson R, Dreborg SKG. Indirect contact with pets can confound the effect of cleaning procedures for reduction of animal allergen levels in house dust. Pediatr Allergy Immunol 1994;5:136-9.

25. Ehnert B, Lau-Schadendorf S, Weber A, Schulz J, Wahn U. Sensitization to indoor allergens in infants at age 1 [abstract]. $J$ Allergy Clin Immunol 1993;91:324.

26. Wickman M, Nordvall SL, Pershagen G, Sundell J, Schwartz B. House dust mite sensitization in children and residential characteristics in a temperate region. J Allergy Clin Immunol 1991;88: $89-95$.

27. Wahn U. Allergen exposure, sensitization and bronchial hyperreactivity. In: Basomba A, Sastre $I$, editors. Proceedings I, XVI European Congress of Allergology and Clinical Immunology. Bologna, Italy: Monduzzi Editore; 1995. p. 281-90.

28. Kuehr J, Frischer T, Meinert R, Barth R, Forster J, Schraub S, et al. Mite allergen exposure is a risk for the incidence of specific sensitization. J Allergy Clin Immunol 1994;94:44-52.

29. Warner A, Björkstén B, Munir AKM, Möller C, Schou C, Kjellman N-IM. Childhood asthma and exposure to indoor allergens: low mite levels are associated with sensitivity. Pediatr Allergy Immunol 1996:7:61-7.

30. Thre $\mathrm{E}$, Zetterström $\mathrm{O}$. Increase in non-specific bronchial responsiveness after repeated inhalation of low doses of allergen. Clin Exp Allergy 1993;23:298-305.

31. Dreborg $\mathrm{S}$. Bronchial provocation tests with biologically standardized allergenic preparations. In: Mellilo G, Marone A. Norman PS, editors. Respiratory allergy, clinical immunology, vol. 2. Philadelphia: CW Decker, 1990. p. 185-91.

32. Dreborg S, Basomba A, Belin L, Durham S, Eriksson NE, Frostad $A B$, et al. Biological equilibration of allergenic preparations. Methodological aspects and reproducibility. Clin Allergy 1987;17:537-50. 